\title{
Asperger syndrome from childhood into adulthood
}

\section{Tom Berney}

\begin{abstract}
Asperger syndrome, a form of autism with normal ability and normal syntactical speech, is associated with a variety of comorbid psychiatric disorders. The disorder is well known to child psychiatry, and we are beginning to recognise the extent of its impact in adulthood. The article reviews the diagnosis and assessment of Asperger syndrome and its links with a wide range of psychiatric issues, including mental disorder, offending and mental capacity. It also describes the broader, non-psychiatric management of Asperger syndrome itself, which includes social and occupational support and education, before touching on the implications the disorder has for our services.
\end{abstract}

This article is the second in the series entitled 'Life-span psychiatry', which considers the developmental psychiatry of adulthood. The first article (Zwi \& York, 2004; Invited commentaries: Asherson, 2004; Coghill, 2004, this issue) looked at attention-deficit hyperactivity disorder. Subsequent topics will include early developmental aspects of psychopathy and psychosis, and training implications.

Asperger syndrome comes not only with its own characteristics (Box 1), but also with a wide variety of comorbid conditions such as depression, anxiety, obsessive-compulsive disorder, attention-deficit hyperactivity disorder (ADHD) and alcoholism, and relationship difficulties (including family/marital problems) (Tantam, 2003). It may predispose individuals to commit offences and can affect their mental capacity and level of responsibility as well as their ability to bear witness or to be tried. The syndrome can colour psychiatric disorder, affecting both presentation and management, for children and adults across a wide range of functional ability. Families have taken an active legalistic approach, alleging misdiagnosis and mistreatment and demanding clarity as to the relationship between Asperger syndrome and other diagnostic concepts.

Seeking to describe the nub of this syndrome, Asperger coined the term 'autistic psychopathy' in 1944 to distinguish its innate social distance from that which develops later in schizophrenia; the concept was elaborated by van Kraevelen in 1963, Lorna Wing in 1981 and, most recently, Christopher Gillberg (Gillberg, 1998). There have been different interpretations of the syndrome and it has become included in the group of autistic-spectrum disorders.
This review focuses primarily on clinical issues: more academic aspects have been reviewed by Volkmar et al (2004).

\section{Diagnostic classification}

As in autism, Asperger syndrome shows impaired reciprocal social interaction and restricted, repetitive or stereotyped patterns of behaviour, interests and activities. Unlike autism, intellectual ability and syntactical speech are normal. Wing and Gillberg place the emphasis on current presentation of normal IQ and speech, but ICD-10 and DSM-IV require their presence from early life. The latter presentation is unusual but was stipulated in order to define a disorder that would be an alternative to autism (rather than just a variant or subtype). It is debatable whether many of the cases described by Asperger would have met ICD or DSM criteria.

Gillberg and colleagues proposed a set of disgnostic criteria that approximate to Asperger's original clinical descriptions (Leekam et al, 2000). Various symptoms have been suggested as distinguishing Asperger syndrome from 'highfunctioning autism' (i.e. autism without generalised learning disability) and the issue is clouded by the variety of definitions in use. When allowance is made for ability, there appears to be little real difference between the two except in terms of severity (Kugler, 1998; Gilchrist et al, 2001; Howlin, 2003) although self-awareness remains to be explored (Tantam, 2003).

Tom Berney is a consultant in developmental psychiatry with the Northgate \& Prudhoe NHS Trust (Prudhoe Hospital, Prudhoe, Northumberland NE42 5NT, UK. E-mail: t.p.berney@ncl.ac.uk) and at the Fleming Nuffield Child Psychiatry Unit, Newcastle upon Tyne. He is also honorary consultant to European Services for People with Autism, a registered charity that provides community services. 


\section{Box 1 Characteristics of Asperger syndrome in adulthood}

Childhood onset

Limited social relationships - social isolation

- Few/no sustained relationships; relationships that vary from too distant to too intense

- Awkward interaction with peers

- Unusual egocentricity, with little concern for others or awareness of their viewpoint; little empathy or sensitivity

- Lack of awareness of social rules; social blunders

Problems in communication

- An odd voice, monotonous, perhaps at an unusual volume

- Talking 'at' (rather than 'to') others, with little concern about their response

- Superficially good language but too formal/stilted/pedantic; difficulty in catching any meaning other than the literal

- Lack of non-verbal communicative behaviour: a wooden, impassive appearance with few gestures; a poorly coordinated gaze that may avoid the other's eyes or look through them

- An awkward or odd posture and body language

Absorbing and narrow interests

- Obsessively pursued interests

- Very circumscribed interests that contribute little to a wider life, e.g. collecting facts and figures of little practical or social value

- Unusual routines or rituals; change is often upsetting

(After Gillberg et al, 2001)

\section{Is the label useful?}

Autistic-spectrum disorders comprise a group of disorders of varied form and intensity that fall on a dimensional spectrum of severity that shades into 'neurotypical normality' (i.e. the absence of an autisticspectrum disorder). In clear-cut cases (exemplified by Dustin Hoffman's character in the film Rain Man) individuals are helped by a categorical approach that gives a shorthand explanation of their difficulties. The validity of categorisation is less clear for those whose milder symptoms put them near the 'normality' end of the spectrum as well as for those whose florid symptomatology is limited to only some of the key diagnostic areas. Even less clear is the position of individuals who, appearing to be superficially normal, have some of the subtle but disabling psychological deficits associated with autism, affecting executive function, attention, perception and comprehension. Closer examination often reveals a mix of specific developmental disabilities which, should they include language and social impairment, it is tempting to classify under autistic-spectrum disorder, sweeping in many eccentric and isolated personalities.

This desire to place all socially impaired patients somewhere on the autistic spectrum is offset by efforts to split off syndromes such as pathological demand avoidance (Newson et al, 2003) and semantic pragmatic (Bishop \& Norbury, 2002) or multiplex developmental disorders (Towbin et al, 1993). Complicated by synonyms such as righthemisphere or non-verbal learning disorders (Fitzgerald, 1999), the result is a confusing grouping of specific disabilities on which we impose recognisable constellations of clinical disorder (WillemsenSwinkels \& Buitelaar, 2002).

Where should we set the boundaries of a dimensional disorder? As with the personality disorders, there needs to be a diagnostic threshold: it might be the point at which the behaviour causes distress (either to the patient or to those around) or significant problems in social functioning and performance, or at which it requires treatment. But can we fix a threshold in this way? The label of Asperger syndrome may help the bullied schoolboy but be rejected when he becomes a mathematical star enjoying university: a functional distinction of permanent traits from a disorder that depends on the setting as much as the innate characteristics. That the presence of an autistic-spectrum disorder may make it difficult for the individual to acknowledge his disability complicates this concept.

Autism used to be considered a rare disorder with a population prevalence of about $0.04 \%$, of whom $70-80 \%$ had a significant learning disability. More recently, the extended spectrum of autistic disorder gives a population prevalence of at least $0.6 \%$, of whom $70-90 \%$ are of normal learning ability. So far, the evidence is that this shift can be explained by 
changing concepts and diagnostic boundaries as well as by the wider recognition of autistic-spectrum disorders rather than by any real substantial increase (Fombonne, 2003).

As the developmental model embraces more of psychiatry, it appears increasingly difficult to make a sharp distinction between autisticspectrum disorder and other entities such as the personality disorders, simple schizophrenia and catatonia; at times the diagnostic label reflects the clinician's specialty rather than the syndrome.

\section{How does Asperger syndrome change with age?}

Like many other developmental disorders, autisticspectrum disorders improve with age, although the symptoms, such as stereotypies, may resurface with arousal, whether from anxiety, boredom, anger or excitement. However, while the more overt symptoms of autism are usually at their most florid in early childhood, the symptoms of Asperger syndrome may only become obvious with the social and functional demands of adolescence.

Besides an innate link with varied comorbidity, there is the stress of growing up with Asperger syndrome that arises from unrecognised disability, limited achievement and a sense of failure, often revealed by an increasing contrast with more autonomous and successful siblings or peers. In addition, the syndrome distorts relationships with family and peers, who can be infuriated by the person's self-centred insensitivity, obsessiveness and rigid inflexibility. All this can add secondary disability and result in a degree of dependency that is out of proportion to the person's intellectual ability (Howlin et al, 2004).

Over a third of people with autistic-spectrum disorders develop epilepsy, the risk being linked to the degree of developmental delay and receptive language deficit. There is no specific study of epilepsy in Asperger syndrome, although the relatively normal ability and language suggest that the risk is lower, possibly $5-10 \%$, and that it is more likely to start later, in adolescence or early adulthood (Tuchman \& Rapin, 2002).

\section{The presentation in adulthood}

Asperger syndrome in adults presents with particular, and often subtle, difficulties, especially in communication, social relationships and interests. Not all individuals are affected as extremely as in the descriptions below. In some it is questionable whether they simply fall within the normal range of variation, particularly male, and whether their behaviour represents psychiatric disorder or isolated, specific developmental characteristics.

\section{Communication}

This is often obviously abnormal, 'conversation' taking the form of one-sided, circumstantial lectures delivered impassively by a seemingly robotic figure with a mechanical voice. However, less obvious conversational abnormality includes unrecognised, underlying discrepancies between verbal and nonverbal language, and between comprehension and expression. These can lead both the affected individual and those around him to misjudge his abilities, expectations being either too high or too low. Very often, reading works where listening has brought incomprehension. Often, the life of someone with Asperger syndrome can be transformed if as much as possible is presented to him in writing.

\section{Social relationships}

These are one-sided, distant or even absent, rather than really reciprocal. Behind this is an unempathic objectivity that results in difficulties that range from understanding friendship (and how friends differ from acquaintances) through to making sexual relationships and grasping the rules that distinguish, for example, seduction from date rape. The person is not uninterested in relationships but, misunderstanding them, is too intense or too detached.

\section{Interests}

A key feature of Asperger syndrome is repetitive or focused activities. At their most extreme, these result in an eccentric whose life is characterised by its routine, rigid and systematic approach and whose world might narrow down to railway timetables or stamp collecting. Any development of an interest remains circumscribed (for example, restricted simply to collecting more of something rather than gaining wider expertise) and, far from becoming the basis of a social network, is enjoyed in solitude.

\section{Psychiatric diagnosis and assessment}

Diagnosis on its own is of limited value, but it is the gateway to a great deal of information, specialist groups and resources, including financial support. It is often not recognised that a diagnosis is simply a working hypothesis: it is a clinical judgement that 
has to strike a balance between being too broad and being too narrow; and it is a process that can evolve with time and changing circumstances. It is essential, therefore, that it is categorical and that everyone involved appreciates its purpose, as its cutoff points will depend on whether it is

- for research - excluding any doubtful cases;

- clinical - a best guess to guide further treatment;

- administrative - giving access to services or resources, or being part of legal assessments regarding mental capacity, reliability as a witness, fitness to plead and level of responsibility.

However, whatever its purpose, a diagnosis should only be given if it has a useful function.

Assessment follows diagnosis and it should be broad and multidisciplinary (Howlin, 2000), in particular, taking account of:

- cognitive ability - identifying discrepancies between receptive and expressive, verbal and non-verbal communication;

- functional ability - acknowledging the extent to which problems in executive function and limited empathy can disable someone who is otherwise very able; strengths should be identified, particularly any special talents that may become foundations in life;

- comorbid developmental disabilities, notably ADHD, tics and dyspraxia.

\section{Diagnosis and assessment in Asperger syndrome}

Many people with Asperger syndrome misperceive their circumstances. It is therefore essential to obtain a comprehensive picture of them that includes the accounts of others such as parents, friends, teachers and employers (Green et al, 2000).

A report of the assessment should be given to the patient in writing, to avoid misunderstandings that might arise with spoken communication.

If Asperger syndrome is suspected, diagnosis needs a clinician familiar with the syndrome as well as with the alternatives. The diagnostic judgement should be based on a developmental history (that takes a lifelong perspective) combined with a present state examination designed to identify the features of autism.

\section{Diagnostic instruments}

Diagnostic instruments help clinicians in the systematic collection of the right information, which they might match against criteria that, although evolving, hold them to a consistent threshold and a broad conceptual construct. Matching may be refined by an algorithm, but in practice, such mechanical simplicity can be misleading, particularly when there is a comorbid overlay.

Furthermore, although a number of diagnostic instruments have been developed to identify autism, the few that have been designed specifically for Asperger syndrome are mostly intended as screening questionnaires. They vary in the extent to which they are structured, ranging from the very specific, selfrating Australian Questionnaire (Attwood, 1999) through to the Asperger Syndrome Diagnostic Interview (ASDI), a simple framework that has good interrater reliability (Gillberg et al, 2001).

The more formal, structured interviews, such as the Autism Diagnostic Interview - Revised (ADI-R; Lord et al, 1994), were initially developed as research instruments to identify children with clear-cut autism. Broader instruments have since evolved, such as the Diagnostic Instrument for Social and Communication Disorders (DISCO). The Autism Diagnostic Observation Schedule (ADOS; Lord et al, 2000), a subject interview designed to elicit the signs of autism, has a module for able and fluent adolescents and adults. The International Molecular Genetic Study of Autism Consortium intend to publish their Family History Interview (FHI), a set of schedules that includes matching subject and informant interviews as well as a scale to record observed behaviour. Whatever instrument is used, it is essential that it takes account of childhood as well as current symptoms.

Many people will have diagnosed themselves from books and self-rating scales and are seeking formal confirmation. A screening assessment focusing only on current symptoms may be relatively brief, particularly if it complements a psychiatric interview. A more definitive diagnostic interview can require several hours and is not something to undertake without good reason.

\section{Differential diagnosis and comorbidity}

Comorbid pathology is frequent and Asperger syndrome has been linked with a number of particular disorders (Green et al, 2000; Tantam, 2003). This association has sometimes arisen from diagnostic confusion but it also reflects a real predisposition (Box 2). After helping people come to terms with the diagnosis and its implications (something probably best done by the nonpsychiatric services described below), psychiatric management usually lies in the recognition and management of the comorbid disorders. 


\section{Box 2 Differential diagnoses}

Anxiety states

- elective mutism

- social phobia

- generalised anxiety disorder

- panic disorder

Attention-deficit hyperactivity disorder

Schizophrenia (particularly treatmentresistant)

- paranoid

- catatonic

- simple

Personality disorders

- avoidant

- schizoid

- anankastic

- dissocial

Obsessive-compulsive disorder

\section{Schizophrenia}

Despite Asperger's early intent, it was only in 1971 that autism was distinguished from schizophrenia, although a number of subsequent reports have suggested that it might yet be identified as a predisposing factor. The similarity of Asperger syndrome to a preschizophrenic, schizoid personality disorder as well as to residual schizophrenia, in both clinical presentation and neurobiology, has led to a diagnostic confusion that has not taken account of their differing developmental trajectories. Such suggestions of a return to the concept of the unitary psychosis arise where association has been mistaken for causation - both may have similar underlying anomalies giving rise to similar, but not identical symptomatology (Box 3).

Although it is doubtful that an autistic-spectrum disorder predisposes to schizophrenia (Tantam, 2003; Howlin et al, 2004), it certainly does not protect. If psychosis arises, early treatment is so important to prognosis that it should not be delayed by diagnostic doubts. However, it must be recognised that, once a patient has been established on neuroleptics, it can be difficult to disentangle the two disorders.

\section{Affective disorders}

Affective disorders occur more frequently in Asperger syndrome than in the normal population. The inability to label internal feelings can lead to their expression in confusing and even bizarre ways.
Chronic dysphoria may merge with more clearcut depression, anxiety with phobic states, and overarousal with panic. All can respond to serotonergic medication. This raises the issue of how readily and how early medication should be tried, particularly in the light of the reservations about the use of the serotonergics in depression (Nutt, 2003). Although one positive randomised controlled trial is available (McDougle et al, 1995a), most of the evidence of their

\section{Box 3 Mistaking Asperger syndrome for psychosis}

- Thoughts expressed simply and concretely by someone who has difficulty in describing internal symptoms can sound very like hallucinations.

- Occasionally, a very vivid account of events is held consistently but is plainly false; these perceptions do not seem to trouble the individual or to be associated with any functional change. There is the sense that the individual is living in a 'video world', only detectable and comprehensible if the interviewer has also seen the video.

- High arousal in a developmental disorder can produce an acute and transient psychotic state with hallucinations and thought disorder.

- Incomplete answers can sound like psychotic symptoms. For example, a bald report, without elaboration or context, of everyday teasing can sound like persecutory delusions.

- A pragmatic difficulty in appreciating the extent or limitations of someone else's knowledge of a topic, coupled with a tendency to obsessionality, can result in overinclusive, irrelevant speech that mimics schizophrenic thought disorder.

- Impassivity and a lack of awareness of the emotional climate can look like inappropriate or blunted affect.

- The catatonic symptoms (e.g. odd mannerisms and postures, freezing or difficulty in initiating movement) that occur in a variety of neurological conditions, including schizophrenia, can also occur in autistic-spectrum disorders (Wing \& Shah, 2000).

- The slow and reluctant response of patients asked to perform a task that has no meaning for them resembles the negative symptoms of schizophrenia.

- Autistic-spectrum disorders can show improvement with neuroleptics (Campbell et al, 1996). 
efficacy in autism comes from open trials and is limited to the longer-established SSRIs. Individual patients resort to 5-hydroxytryptophan or St John's wort.

\section{Obsessive-compulsive disorder}

A natural reaction to the mess of everyday life is to establish order (although the greater the success in achieving a set, predictable world, the greater the distress when faced with novelty and change). For a person with Asperger syndrome this reaction may become pathological: for example, the commonplace collection of objects can come to dominate his life as well the lives of those around him, and if all sense of proportion is lost an obsession can lead to criminal offending.

Management includes the use of standard techniques to cope with obsessions and routines diversion, environmental change, pictorial or written preparation for change, and the introduction of alternative rules and routines as well as of limits.

Serotonergic drugs can reduce the obsession, although finding the right drug may take a number of trials and, once found, its effect may be only partial and temporary. Medication does allow the introduction of changes in an individual's life and of behaviour that might reduce the likelihood of recurrence.

Obsessional traits run through much of biological psychiatry as well as being an overlapping familial trait in autistic-spectrum disorders (Hollander et al, 2003). The absence of internal resistance and anxiety in autistic disorders has caused some to question whether this is truly obsessive-compulsive disorder (Baron-Cohen, 1989), particularly because the content of the thoughts and the form of compulsive behaviour differ from that of the 'neurotypical person' (McDougle et al, 1995b). All the same, as the management is similar, the distinction may be academic.

\section{Other developmental disorders}

Asperger syndrome has been linked with ADHD, tic disorders (including Tourette syndrome) and various specific learning disabilities, notably disorders of executive function and motivation that make it difficult for an individual to develop an occupation.

\section{Alcoholism}

Alcohol is an effective tranquilliser, particularly for someone who finds social groups uncomfortable. Asperger syndrome can add a compulsive quality to social drinking and encourage isolated drinking ungoverned by normal societal conventions. The evidence for alcohol misuse in Asperger syndrome is more anecdotal than quantified by systematic research, but its significance lies in the quality of its psychopathology rather than in any increase in frequency of drinking.

\section{Offending}

A reluctance to link any disorder with criminality, a tolerance for disturbance in anybody with disability and an unwillingness to prosecute where conviction is uncertain, all combine to mask any association between psychiatric disorder and offending. However, there is a case for suspecting the undiagnosed syndrome in a number of forensic presentations (Box 4) as a number of predispositional elements come with Asperger syndrome (Box 5). Various factors combine to make violent aggression relatively frequent in Asperger syndrome: 'hitting people' was a problem in $40 \%$ of a large case series (Tantam, 2003).

Many of the characteristics listed in Box 5 affect the individual's capacity to make valid decisions, thus limiting his level of responsibility. Whether someone is identified as an 'offender' (as distinct from someone who has committed an offence) depends on chance factors in their environment such as the effectiveness of their supervision, the recognition of autistic-spectrum disorder and the understanding of those around.

\section{Reliability as a witness}

The report of an event depends on what the observer actually saw, their interpretation of the scene and on their memory. Certain characteristics of Asperger syndrome, such as those listed in Box 6, colour individuals' understanding and recall of a situation. Consequently, in deciding on fitness to act as a witness it is important to assess, first, the individual's ability to give a reliable account. Here it is essential to get enough specific, concrete, verifiable material such as details of the scene

\section{Box 4 Forensic presentations}

The following criminal behaviours might indicate undiagnosed Asperger syndrome:

- Obsessive harassment (stalking)

- Inexplicable violence

- Computer crime

- Offences arising out of misjudged social relationships 


\section{Box 5 Characteristic features of Asperger syndrome that predispose to criminal offending}

- An innate lack of concern for the outcome can result in, for example, an assault that is disproportionately intense and damaging. Individuals often lack insight and deny responsibility, blaming someone else; this may be part of an inability to see their inappropriate behaviour as others see it.

- An innate lack of awareness of the outcome that allows individuals to embark on actions with unforeseen consequences; for example, fire-setting may result in a building's destruction, and assault in death.

- Impulsivity, sometimes violent, can be a component of comorbid ADHD or of anxiety turning into panic.

- Social naïvety and the misinterpretation of relationships can leave the individual open to exploitation as a stooge. Their limited emotional knowledge can lead to a childish approach to adult situations and relationships, resulting, for example, in the mistaking of social attraction or friendship for love.

- Misinterpreting rules, particularly social ones, individuals find themselves unwittingly embroiled in offences such as date rape.

- Difficulty in judging the age of others can lead the person into illegal relationships and acts such as sexual advances to somebody under age.

- Overriding obsessions can lead to offences such as stalking or compulsive theft. Admonition can increase anxiety and consequently a ruminative thinking of the unthinkable that increases the likelihood of action.

- In formal interviews, misjudging relationships and consequences can permit an incautious frankness and the disclosure of private fantasies which, although no more lurid than any adolescent's, are best not revealed.

- Lacking motivation to change, individuals may remain stuck in a risky pattern of behaviour.

(e.g. the clothing worn and the colour and pattern of the wallpaper), as well as of the events preceding and following the episode, to be able to identify any temporal confusion.

Box 6 Features of Asperger syndrome that affect an individual's reliability as a witness

- The risk of misinterpretation of what he has seen or heard.

- Difficulty with the dimension of time. Although the person may recall the sequence of events correctly, his perception of the relative periods of intervening time may be so inaccurate as to make it unclear as to whether he is recounting something that happened the previous day, week or year.

- Difficulty in distinguishing his own actions from those of others, which may extend to a confusion of reality with observed fiction.

- Difficulty with the normal structure of official interviews, whether in the police station or the witness box, where the unfamiliar surroundings and circumstances will increase his disabilities.

- The interview can be distorted by the misinterpretation of rules and relationships, with undue compliance complicated by a rigid tendency to adhere to (and believe in) a story once it is in his head.
Second, the individual's ability to give a good account and to comprehend and to respond to questions must also be assessed. Allowance must be made for communication problems such as the use of words without understanding their significance, the characteristic, very literal comprehension, and the inability to take in non-verbal components. Here the use of visual aids, particularly written text, can help communication, which may be made even more friendly by the use of a computer.

There is a risk that individuals with Asperger syndrome may not be recognised as vulnerable adults, particularly if they have a good academic awareness of right from wrong. How they present themselves becomes of particular importance with the removal of the right to silence, as it can affect fitness to plead (Gray et al, 2001).

\section{Broader (non-psychiatric) management}

Structure and support can reduce the stress of everyday life to the point that an individual with Asperger syndrome can function (whether in education, employment or family domesticity), and every patient needs to be seen in this context (Powell, 2002). Education is central as, although innate deficits can improve with time, people with the syndrome have to learn consciously the skills that most acquire intuitively. Examples are the unwritten 
rules of social life such as how to make social overtures, to complain and to avoid exploitation (Segar, 1997).

\section{Education \\ School}

Life in a small primary school, with consistent classmates, the same classroom and the same teacher, can be sufficiently straightforward for children to cope. It is when they move from this relative stability into the secondary school confusion of different sets and multiple teachers that they are tested and their true degree of disability becomes apparent.

Education needs to be unusually broad and explicit as these students develop on a wide variety of fronts. Besides supervision to cope with organising and completing academic tasks, they will need support to develop self-help skills in everyday areas such as shopping, laundry and cleanliness (where obsessionality may block self-care) and social skills (conversation, dating, coping with authority, asking for help) (Attwood, 2000). All of these have to be taught if individuals with Asperger syndrome are to develop the sense of a positive identity and competence that comes more naturally to normal, 'neurotypical' young people.

\section{Further education}

Further education gives the opportunity to learn the skills necessary to cope with employment, higher education or simply everyday life. Although sector colleges are becoming better geared to students with special needs, they are limited by their structure, funding and expertise. People who are unusually awkward, sensitive, violent or disturbed may require a place at a specialist college. These provide a compatible peer group, staff with understanding and expertise, and considerable support.

Funding for up to 3 years of specialist further education can be obtained for individuals between the ages of 16 and 25 years. It is intended for those who want to progress beyond school-leaving but do not have the skills or ability to cope with sector college.

\section{Higher education}

Although social demands may be less than in other forms of education, the lack of structure and supervision defeat many who are otherwise academically able. In England, the Special Education Needs and Disability Act 2001 (SENDA) has established legal rights for disabled students and has outlawed discrimination in education at all ages. Students can declare their disability on application to a university or college.

A number of universities have put in place measures to help students with autistic-spectrum disorders (Box 7). Such measures may create a more sympathetic setting than any previously experienced and bring the hope that earlier disturbance, the consequence of an uncomfortable environment, will evaporate. However, no matter how specialist the college or attuned the university, it cannot be a substitute for an adolescent psychiatric unit or a therapeutic community if it is to retain an academic climate.

\section{Employment}

People with Asperger syndrome often find themselves in a maze guided by disability specialists with limited knowledge of the disorder. Their difficulties start with the skills required for a job interview. Then there is the need to cope with people, the unpredictable and the unexpected that are part of many jobs. Even jobs that seem ideal, for example that capitalise on special interests or a methodical approach, can fail should an individual become bogged down in ritual slowness or should his interest take over - an enthusiasm for timetables has to remain subservient to giving others the information. The successful post takes these factors into account and builds in support so that, when things start going wrong, they are quickly detected and rectified. Such help may come from a dedicated individual, the job coach, but eventual success will depend on how far the setting and, in particular, others at work are able to take over.

Several specialist schemes have been developed, most notably Prospects, a programme run by the National Autistic Society, which has been very successful in helping people to get and retain jobs, largely at a skilled clerical or technical level. Its experience has been of a workforce characterised by good time-keeping and the ability to get on with work that others might find too repetitive, without being distracted by the temptation to waste time in gossip or to engage in promotion-seeking office politics.

\section{Social care}

Many people will need continued everyday support that may range from a regular visitor through to someone living in the same house. For some, this will be to ensure that they eat, care for themselves and continue to take part in society. For others, it will be to help them to avoid or disentangle themselves from the predicaments that arise from their social naïvety, lack of foresight, or odd 
Box 7 Measures adopted by universities to help students with autistic-spectrum disorders

- A disability support service that has the skills and status to liaise with departments to help them to adapt to the needs of these students (e.g. by extending work deadlines, or modifying arrangements to enable a student to complete placements, practicals or fieldwork).

- A public education programme and specific training, for both staff and students, to make them aware of autistic-spectrum disorders and their difficulties, and of the support service.

- A keyworker, usually a postgraduate student or member of staff, to whom a student can go for immediate advice or pastoral support.

- Specialist tuition to develop suitable study skills (e.g. language skills, structuring their work and organising their approach to studying).

- The use of aids such as handouts and tape recordings of lectures.

- Help with managing allowances, budgeting and everyday skills such as laundry and shopping. Mentorship schemes, possibly through the students' union, can draw in other students.

- A support network for isolated students. Group seminars, tutorial and study groups can all contribute, as can paired or group assignments and recreational activities.

- An introductory programme that includes first contacts (e.g. with a tutor), good induction and orientation (e.g. with maps of the campus and lists of important contacts and their roles), positive family contacts when appropriate and, above all, a flexible approach that adapts to different students and their particular needs.

- Safe places on campus where students can withdraw, calm down and refocus when anxiety or anger threaten to get out of control. The involvement of all elements, including the campus police and the students' union, can allow fragile students to complete their course successfully as well as learn to manage their over-arousal.

- A clear and realistic plan for the student's exit from college when they have completed their course. There should be reviews in the final year and, if the student is under 25 years old, Connexions (the careers and employment advisory agency designed to help people throughout adolescence and into adulthood) can be contacted. appearance and behaviour (which can make them the target of children's abuse and the neighbourhood scapegoat). Some will continue to get this support from parents, others may acquire a partner or friend, and a few will need to employ someone on a formal basis. Many find support irritating and difficult to accept.

\section{Family support}

Asperger syndrome adds an unusual complexity to the family, and similar traits in other members may either compound or buffer matters. Parents, partners and siblings may need formal counselling or group work, particularly if they themselves have communication difficulties, an unusual objectivity or a focused persistence. An Asperger support group can offer substantial help.

\section{Service implications}

People with Asperger syndrome fall into therapeutic limbo, too able for learning disability services and foreign to general psychiatry. A political groundswell, driven by families, is pressing for better psychiatric services that are sufficiently familiar with the disorder for it not to disadvantage patients. Psychiatric resources were insufficient even before autism achieved 'popularity'. Consequently, it is unrealistic to hope for separate specialist facilities for out-patients, let alone in-patients, except at a regional level. Existing resources will need to become autism-friendly, something that is achieved by staff training as much as by environmental change.

It helps that the label of 'autism' attracts substantial funding (more than 'personality disorder') and that there are a variety of specialist support services. However, although good specialist care services can provide comfortable community placements for very disturbed people, some psychiatric services have found themselves overstretched by over-ambitious care providers that take on more than they can cope with. Supporting and influencing such services in their development might avoid this problem.

The psychiatrist has to keep pace with the growing awareness of patients and the public, as much to exclude Asperger syndrome as to recognise it and its consequences. The effects of comorbid disorder have to be disentangled from the underlying syndrome, and the diagnosis should be used selectively rather than as a catchall for any unclassifiable personality or disorder. The recognition of developmental disorder in an everincreasing range of social and interpersonal difficulties carries the risk of retracing earlier 


\section{Box 8 Key reading}

Attwood (1999) Asperger's Syndrome

Haddon (2002) The Curious Incident of the Dog in the Night-Time

Howlin (2004) Autism and Asperger SyndromePreparing for Adulthood

Klin et al (2000) Asperger Syndrome

Tantam (2003) 'The challenge of adolescents and adults with Asperger syndrome'

psychoanalytic paths that medicalised the human condition.

All psychiatric specialties need to develop sufficient knowledge and skill in dealing with autistic-spectrum disorders to avoid accusations of incompetence (Box 8). An initial step would be to agree the minimum level of expertise and training.

\section{References}

Asherson, P. P. (2004) Bridging the service divide. Invited commentary on Attention-deficit hyperactivity disorder in adults. Advances in Psychiatric Treatment, 10, 257-259.

Attwood, A. (1999) Asperger's Syndrome. London: Jessica Kingsley.

Attwood, T. (2000) Strategies for improving the social integration of children with Asperger syndrome. Autism, 4, 85-100.

Baron-Cohen, S. (1989) Do autistic children have obsessions and compulsions? British Journal of Clinical Psychology, 28, 193-200.

Bishop, D. V. M. \& Norbury, C. F. (2002) Exploring the borderlands of autistic disorder and specific language impairment: a study using standardised diagnostic instruments. Journal of Child Psychology and Psychiatry and Allied Disciplines, 43, 917-929.

Campbell, M., Schopler, E., Cueva, J., et al (1996) Treatment of autistic disorder. Journal of the American Academy of Child and Adolescent Psychiatry, 35, 134-143.

Coghill, D. (2004) Understudied and underrecognised. Invited commentary on Attention-deficit hyperactivity disorder in adults. Advances in Psychiatric Treatment, 10 338-340.

Fitzgerald, M. (1999) Differential diagnosis of adolescent and adult pervasive developmental disorders/autism spectrum disorders (PDD/ASD). A not uncommon diagnostic dilemma. Irish Journal of Psychological Medicine, 16, 145-148.

Fombonne, E. (2003) Epidemiological surveys of autism and other pervasive developmental disorders: an update Journal of Autism and Developmental Disorders, 33, 365382.

Gilchrist, A., Green, J., Cox, A., et al (2001) Development and current functioning in adolescents with Asperger syndrome. A comparative study. Journal of Child Psychology and Psychiatry and Allied Disciplines, 42, 227-240.

Gillberg, C. (1998) Asperger syndrome and high-functioning autism. British Journal of Psychiatry, 172, 200-209.

Gillberg, C., Gillberg, C., Rastam, M., et al (2001) The Asperger Syndrome (and high-functioning autism) Diagnostic Interview (ASDI). A preliminary study of a new structured clinical interview. Autism, 5, 57-66.

Gray, N. S., O'Connor, C., Williams, T., et al (2001) Fitness to plead: implications from case-law arising from the Criminal Justice and Public Order Act 1994. Journal of Forensic Psychiatry, 12, 52-62.
Green, J., Gilchrist, A., Burton, D., et al (2000) Social and psychiatric functioning in adolescents with Asperger syndrome compared with conduct disorder. Journal of Autism and Developmental Disorders, 30, 279-293.

Haddon, M. (2002) The Curious Incident of the Dog in the Night-Time. London: Jonathan Cape.

Hollander, E., King, A., Delaney, K., et al (2003) Obsessivecompulsive behaviors in parents of multiplex autism families. Psychiatry Research, 117, 11-16.

Howlin, P. (2000) Assessment instruments for Asperger syndrome. Child Psychology and Psychiatry Review, 5, 120129.

Howlin, P. (2003) Outcome in high-functioning adults with autism with and without early language delays: implications for the differentiation between autism and Asperger syndrome. Journal of Autism and Developmental Disorders, 33, 3-13.

Howlin, P. (2004) Autism and Asperger Syndrome - Preparing for Adulthood (2nd edn). London: Routledge.

Howlin, P., Goode, S., Hutton, J., et al (2004) Adult outcome for children with autism. Journal of Child Psychology and Psychiatry and Allied Disciplines, 45, 212-229.

Klin, A., Volkmar, F. R. \& Sparrow, S. S. (eds) (2000) Asperger Syndrome. New York: Guilford Press.

Kugler, B. (1998) The differentiation between autism and Asperger syndrome. Autism, 2, 11-32.

Leekam, S., Libby, S., Wing, L., et al (2000) Comparison of ICD-10 and Gillberg's criteria for Asperger syndrome. Autism, 4, 11-28.

Lord, C., Rutter, M. \& Le Couteur, A. (1994) Autism Diagnostic Interview - Revised: a revised version of a diagnostic interview for caregivers of individuals with possible pervasive developmental disorders. Journal of Autism and Developmental Disorders, 24, 659-685.

Lord, C., Risi, S., Lambrecht, L., et al (2000) The Autism Diagnostic Observation Schedule - Generic: a standard measure of social and communication deficits associated with the spectrum of autism. Journal of Autism and Developmental Disorders, 30, 205-223.

McDougle, C. J., Naylor, S. T., Cohen, D. J., et al (1995a) A double-blind, placebo-controlled study of fluvoxamine in adults with autistic disorder. Archives of General Psychiatry, 53, 1001-1008.

McDougle, C. J., Kresch, L. E., Goodman, W. K., et al (1995b) A case-controlled study of repetitive thoughts and behavior in adults with autistic disorder and obsessive compulsive disorder. American Journal of Psychiatry, 152, 772-777.

Newson, E., Le Marechal, K. \& David, C. (2003) Pathological demand avoidance syndrome: a necessary distinction within the pervasive developmental disorders. Archives of Disease in Childhood, 88, 595-600.

Nutt, D. (2003) Death and dependence: current controversies over the selective serotonin reuptake inhibitors. Journal of Psychopharmacology, 17, 355-364.

Powell, A. (2002) Taking Responsibility: Good Practice Guidelines for Services - Adults with Asperger Syndrome. London: National Autistic Society.

Segar, M. (1997) A Survival Guide for People with Asperger Syndrome. Nottingham: NoRSACA. Available at http:// www.autismandcomputing.org.uk/marc2.htm.

Tantam, D. (2003) The challenge of adolescents and adults with Asperger syndrome. Child and Adolescent Psychiatric Clinics of North America, 12, 143-163, vii-viii.

Towbin, K. E., Dykens, E. M., Pearson, G. S., et al (1993) Conceptualizing 'borderline syndrome of childhood' and 'childhood schizophrenia' as a developmental disorder. Journal of the American Academy of Child and Adolescent Psychiatry, 32, 775-782.

Tuchman, R. \& Rapin, I. (2002) Epilepsy in autism. Lancet Neurology, 1, 352-358.

Volkmar, F. R., Lord, C., Bailey, A., et al (2004) Autism and pervasive developmental disorders. Journal of Child Psychology and Psychiatry and Allied Disciplines, 45, 135-170.

Willemsen-Swinkels, S. H. N. \& Buitelaar, J. K. (2002) The autistic spectrum: subgroups, boundaries, and treatment. Psychiatric Clinics of North America, 25, 811-836. 
Wing, L. \& Shah, A. (2000) Catatonia in autistic spectrum disorders. British Journal of Psychiatry, 176, 357-362.

Zwi, M. \& York, A. (2004) Attention-deficit hyperactivity disorder in adults: validity unknown. Advances in Psychiatric Treatment, 10, 248-256.

\section{MCQs}

1 The characteristics of Asperger syndrome include:

a a lack of awareness of the feelings of others

b a lack of speech

c a lack of friendships

d a lack of interest in people

e specialist expertise.

2 People with the syndrome frequently have/have had:

a depression

b a psychotic episode

c alcoholism

d anxiety disorder

e ADHD.
3 A person with Asperger syndrome:

a needs psychiatric treatment

b has very good recall of events

c has difficulty with the unfamiliar and unstructured

d will probably require long-term support

e will probably not develop epilepsy.

4 Asperger syndrome is:

a distinct from autism

b a genetic disorder

c predominantly a disorder of childhood

d part of the autistic spectrum of disorder

e a mild disorder.

5 Asperger syndrome:

a can limit mental capacity to make decisions

b restricts employment

c will probably include several specific learning disabilities

d occurs in about $2 \%$ of the population

e improves with age.

\section{MCQ answers}

\begin{tabular}{|c|c|c|c|c|}
\hline 1 & 2 & 3 & 4 & 5 \\
\hline $\mathrm{T}$ & a $\mathrm{T}$ & a $F$ & a $F$ & $\mathrm{a}$ \\
\hline $\mathrm{F}$ & $b F$ & b F & $\mathrm{b} T$ & b \\
\hline $\mathrm{T}$ & C F & c $\mathrm{T}$ & c F & \\
\hline $\mathrm{F}$ & $\mathrm{d} T$ & $\mathrm{~d} T$ & $\mathrm{~d} T$ & $d$ \\
\hline $\mathrm{F}$ & e $\mathrm{T}$ & e $\mathrm{T}$ & e $F$ & $\mathrm{e}$ \\
\hline
\end{tabular}

